\title{
СТАТЬИ
}

УДК $630 * 266$ ЛЕСОВОДСТВЕННО-МЕЛИОРАТИВНЫЕ ОСОБЕННОСТИ
ПОЛЕЗАЩИТНЫХ НАСАЖДЕНИЙ КРАСНОДАРСКОГО КРАЯ

Михин В.И., Михина Е.А.

ФГБОУ ВО «Воронежский государственный лесотехнический университет имени Г.Ф. Морозова»,Воронеж, е-mail:dr.mikhin2018@yandex.ru

Защитные искусственные лесные насаждения Краснодарского края формируют экологический каркас ландшафта. Лесоводственные и мелиоративные особенности таких биологических объектов проявляются в зависимости от лесокультурных, агротехнических приёмов создания, их общего состояния, роста и продуктивности. В смешанных культурах в возрасте 25 лет с участием акации белой, груши и яблони лесной формируется ажурная структура. Тополь является быстрорастущей породой и имеет наибольшие показатели роста по отношению к сопутствующим породам. В возрасте 25-28 лет акация белая превосходит своих спутников по диаметру и высоте на 9,6-56,4\% и имеет сохранность растений 56,3-61,5\%. Насаждения из ясеня зелёного в молодом возрасте (8 лет) имеют сохранность около $80 \%$, где их ветрозащитная высота составляет 9,8 м и средний диаметр - 4,2 см. Такие насаждения по критериям лесоводственно-мелиоративной оценки формируют высокий показатель (5а). Культуры из абрикоса обыкновенного в возрасте 9-21 года представлены ажурной структурой с сохранностью породы 68,2-71,8\%. Они достигают высоты 3,4-7,5 м при среднем диаметре 4,8-10,8 см. У ореха грецкого в возрасте 17 лет в защитных насаждениях средний диаметр составляет 12,2 см, высота - 7,2 м. Насаждения из гледичии обыкновенной, ореха грецкого и акации белой в возрасте 25-30 лет формируют выпуклый поперечный профиль, что важно учитывать при формировании эффективных структур насаждений. Наибольший рост в высоту у гледичии обыкновенной, акации белой и ореха грецкого наблюдается на чернозёме обыкновенном среди других типов почв.

Ключевые слова: защитные насаждения, высота, диаметр, лесоводственно-мелиоративная оценка

\section{FORESTRY-RECLAMATION FEATURES PROTECTIVE PLANTATIONS OF KRASNODAR REGION}

\author{
Mikhin V.I., Mikhina E.A. \\ Voronezh State Forestry University named after G.F. Morozov, \\ Voronezh, e-mail:dr.mikhin2018@yandex.ru
}

\begin{abstract}
Protective artificial flatter plantations of Krasnodar territory form the ecological framework of the landscape. Silvicultural and reclamation features of such biological objects are manifested depending on silvicultural, agrotechnical methods of creating their general condition, growth and productivity. In mixed cultures at the age of 25, with the participation of white acacia, pear and forest apple, an openwork structure is formed. Poplar is a fast growing species and has the highest growth rates in relation to the accompanying species. At the age of $25-28$ years, white acacia surpasses its satellites in diameter and height by $9.6-56.4 \%$ and has a plant safety of $56.3-61.5 \%$. Green ash plantations at a young age ( 8 years) are about $80 \%$ safe, where their wind-shelter height is $9.8 \mathrm{~m}$ and an average diameter of $4.2 \mathrm{~cm}$. Such plantations, according to the criteria of silvicultural-reclamation assessment, form a high indicator (5a). Crops of common apricot at the age of $9-21$ years are represented by an openwork structure with a preservation of the breed of $68.2-71.8 \%$. They reach a height of $3.4-7.5 \mathrm{~m}$ with an average diameter of $4.8-10.8 \mathrm{~cm}$. A 17 year old walnut in protective plantations has an average diameter of $12.2 \mathrm{~cm}$, a height of $7.2 \mathrm{~m}$. common heditsia, walnut and white acacia at the age of $25-30$ years form a convex transverse profile, which is important to take into account when forming effective plantation structures. The greatest growth in height in common gleditsia, white acacia and walnut is observed on ordinary chernozem among other types of soils.
\end{abstract}

Keywords: protective plantings, height, diameter, silvicultural-reclamation assessment

Искусственные линейные насаждения формируют экологический каркас в агроландшафтах. При занимаемой площади в Краснодарском крае около 130 тыс. га лесистость пашни составляет 2,9\% [1]. Такие насаждения представлены чистыми и смешанными по составу, в них произрастают определенные виды древесных пород и кустарников с различными агротехническими и лесокультурными приёмами выращивания [2]. Они оказывают определённое влияние на экологические факторы защищённых зон. Их эффективность предопределяет- ся структурой поперечного профиля. Вопросы теории и практики формирования таких защитных насаждений с заданными биометрическими параметрами, позволяющими иметь на пашне высокопродуктивные культуры с максимальным мелиоративным эффектом, рассматриваются в работах В.В. Танюкевича [3], В.И. Турусова, А.А. Лепёхина, А.С. Чеканыхшкина [4], П.Н. Проездова, Д.А. Маштакова [5]. Наши исследования дополняют научную концепцию по формированию законченных систем защитных насаждений в зональном аспекте. 
Цель наших исследований - выявить наиболее эффективные искусственные защитные линейные насаждения на основе их роста в различных почвенных условиях и мелиоративных функций. Это позволит преобразовать агротерритории, улучшить экологию ландшафтов, повысить биопродуктивность агрокультур.

\section{Материалы и методы исследования}

Биометрические показатели в искусственных линейных защитных насаждениях изучались в условиях Тихорецкого (пробн. площади 3, 4, 5), Кореновского (пробн. площади $6,7,8,9)$ и Отрадненского (пробн. площади 10, 11, 12, 13) районов, где почвенный покров на объектах представлен чернозёмом обыкновенном и южным [1;2].

Возраст определялся по архивным материалам и годичным кольцам моделей, средний диаметр с учётом площади сечения среднего дерева, средняя высота по графику соотношений диаметров и высот, сохранность по фактическому показателю c переводом в процентное содержание, конструкция насаждений по количеству просветов в вертикальном профиле древостоя, ходу роста в высоту и по диаметру с использованием модельных деревьев. Лесоводственная и мелиоративная оценка выполнялась по шкале Е.С. Павловского, бонитет по М.М. Орлову [6]. Выявление особенностей по формированию защитных насаждений на основе их роста, лесоводственных и лесомелиоративных свойств позволяет обосновывать параметры оптимальных лесомелиоративных культур на пашне. Экспериментальные данные обрабатывались вариационно-статистическими методами [7].

\section{Результаты исследования и их обсуждение}

Лесомелиоративные комплексы Краснодарского края имеют свои определенные исторические корни в связи со специфическими природно-климатическими условиями. Древесные породы ориентированы на растения естественных насаждений, которые уже давно приспособились к среде обитания [1;2]. Ассортимент пород и агротехника выращивания защитных насаждений нуждаются в совершенствовании и уточнении на зональной основе. Анализ материалов показал (табл. 1), что видовой состав лесополос в основном представлен ясенем зелёным (Яз), акацией белой (Акб), абрикосом обыкновенным (Абр), орехом грецким (Орг), грушей (Грл), яблоней (Ябл) и другими породами.

Opex грецкий (Jaglans regia L.) произрастает как в чистых культурах, так и в смешанных. Обычно защитные насаждения формируются с большим размещением посадочных мест и меньшей густотой, что в дальнейшем предопределяет рост и развитие растений. Так, орех грецкий к 17 годам достигает высоты 7,2 м при среднем диаметре 12,2 см, где сохранность равна 79,6\% и первоначальное размещение культур 5000 шт./га (пробн. площадь 8).

Чистые лесополосы из акации белой (Robinia pseudoacacia L.) при ширине междурядий 2,5 м и расстоянии между растениями в ряду 1,5 м в возрасте 8 лет имеют сохранность 71,6\%, а их средний диаметр равен 4,3 см, средняя высота 2,9 м. Насаждения оцениваются по II классу бонитета (пробн. площадь 7). Их запас составляет всего лишь 10,8 м³/га. В данных насаждениях формируется ажурная конструкция, которая считается наиболее оптимальной в данных почвенно-климатических условиях. При этом лесные полосы имеют высокие показатели по лесоводственной и мелиоративной оценке (5a). Культуры аналогичного породного состава шириной 10,0 м и первоначальной густотой создания 2000 шт./га (размещение 2,5 х 1,5 м) к возрасту 9 лет также имеют сравнительно высокую сохранность (68,2\%), оптимальную конструкцию, высокую лесоводственно-мелиоративную оценку.

В лесополосах при введении акации белой в опушечные ряды, где центральная часть насаждения представлена сопутствующей породой ясенем зелёным, главная порода в возрасте 16 лет имеет сохранность $66,5 \%$, и ее средняя высота составляет 8,9 м, диаметр 10,1 см, что оценивается по высокому классу бонитета. Разница в показателях составляет 17,8-31,3\%, формируется состав 6Акб4Яз. Лесонасаждение защитного назначения характеризуется значимыми показателями оценки в лесоводственном и лесомелиоративном отношении (5б). При ширине 15,0 м формируется продуваемая конструкция, что необходимо учитывать при формировании лесомелиоративных комплексов.

Лесные полосы шириной 12,5 м чистые по составу из ясеня зеленого (Fraxinus lanceolata Borkh.) в возрасте 8 лет достигают высоты 2,8 м при среднем диаметре 4,7 см, где запас 10,9 м³/га, ажурная структура продольного профиля. 
Биометрические показатели искусственных линейных насаждений

\begin{tabular}{|c|c|c|c|c|c|c|c|c|c|c|}
\hline \multirow{2}{*}{$\begin{array}{l}\text { № } \\
\text { пр. } \\
\text { ПЛ. }\end{array}$} & \multirow{2}{*}{$\begin{array}{c}\text { Схема } \\
\text { смешения } \\
\text { Число рядов }\end{array}$} & \multirow{2}{*}{$\begin{array}{l}\text { По- } \\
\text { рода }\end{array}$} & \multirow{2}{*}{$\begin{array}{l}\text { Размещение } \\
\text { посадочных } \\
\text { мест, } \\
\text { м/ширина, м }\end{array}$} & \multirow{2}{*}{$\begin{array}{l}\text { Воз- } \\
\text { раст, } \\
\text { лет }\end{array}$} & \multirow{2}{*}{$\begin{array}{c}\text { Густота } \\
\text { посадки, } \\
\text { шт./га }\end{array}$} & \multirow{2}{*}{$\begin{array}{c}\text { Сохран- } \\
\text { ность, } \\
\%\end{array}$} & \multicolumn{2}{|c|}{ Средние } & \multirow{2}{*}{$\begin{array}{l}\text { Бони- } \\
\text { тет }\end{array}$} & \multirow{2}{*}{$\begin{array}{l}\text { ЛМО } \\
\text { насаж- } \\
\text { дений }\end{array}$} \\
\hline & & & & & & & $\begin{array}{c}\text { диаметр, } \\
\text { см }\end{array}$ & $\begin{array}{c}\text { высо- } \\
\text { та, м }\end{array}$ & & \\
\hline 3 & Яз /5 & Яз & $\frac{2,5 \times 1,5}{12,5}$ & 8 & 2666 & 78,9 & 4,2 & 2,8 & I I & $5 a$ \\
\hline 4 & Акб/4 & Акб & $\frac{2,5 \times 1,5}{10,0}$ & 9 & 2666 & 68,2 & 4,8 & 3,4 & I I & 56 \\
\hline 5 & $\begin{array}{c}\text { Акб-Яз-Яз- } \\
\text { Яз-Акб/5 }\end{array}$ & $\begin{array}{l}\text { Акб } \\
Я_{3}\end{array}$ & $3,0 \times 1,5 / 15$ & 16 & $\begin{array}{c}884 \\
1334\end{array}$ & $\begin{array}{l}66,5 \\
60,1\end{array}$ & $\begin{array}{l}10,1 \\
8,4\end{array}$ & $\begin{array}{l}8,9 \\
5,9\end{array}$ & $\begin{array}{c}\text { Ia } \\
\text { I }\end{array}$ & 56 \\
\hline 6 & Абр/4 & Абр & $3,0 \times 1,5 / 12$ & 21 & 2222 & 71,8 & 10,8 & 7,5 & I & 46 \\
\hline 7 & Акб /6 & Акб & $2,5 \times 1,5 / 15$ & 8 & 2666 & 71,6 & 4,3 & 2,9 & I I & $5 a$ \\
\hline 8 & Орг/3 & Орг & $5,0 \times 4,0 / 15$ & 17 & 500 & 79,6 & 12,2 & 7,2 & I I & 46 \\
\hline 9 & $\begin{array}{c}\text { Шел-Акб- } \\
\text { Акб-Акб- } \\
\text { Грл/5 }\end{array}$ & $\begin{array}{l}\text { Акб } \\
\text { Грл } \\
\text { Шел } \\
\end{array}$ & $3,0 \times 1,0 / 15$ & 28 & $\begin{array}{c}2000 \\
667 \\
667 \\
\end{array}$ & $\begin{array}{l}61,5 \\
50,8 \\
58,3\end{array}$ & $\begin{array}{c}17,2 \\
9,1 \\
15,0\end{array}$ & $\begin{array}{c}15,6 \\
6,8 \\
14,1 \\
\end{array}$ & $\begin{array}{l}\text { I a } \\
\text { I I I } \\
\text { I }\end{array}$ & 56 \\
\hline 10 & $\begin{array}{c}\text { Акб-Т-Т- } \\
\text { Ябл+Грл/4 }\end{array}$ & $\begin{array}{c}\text { Т } \\
\text { Акб } \\
\text { Грл } \\
\text { Ябл } \\
\end{array}$ & $3,0 \times 1,0 / 12$ & 25 & $\begin{array}{l}1666 \\
834 \\
417 \\
417 \\
\end{array}$ & $\begin{array}{l}40,1 \\
56,3 \\
69,5 \\
65,2 \\
\end{array}$ & $\begin{array}{c}20,4 \\
15,5 \\
8,0 \\
7,2 \\
\end{array}$ & $\begin{array}{l}17,6 \\
14,0 \\
6,5 \\
6,1 \\
\end{array}$ & $\begin{array}{l}\text { I a } \\
\text { I a } \\
\text { I I I } \\
\text { I I I }\end{array}$ & 46 \\
\hline
\end{tabular}

В акациево-ясеневых насаждениях (пробн. площадь 5), в силу своих биологических свойств в возрасте 16 лет, главная порода превосходит сопутствующую по среднему диаметру на 1,7 см, средней высоте на 3,0 м и сохранности растений на $6,4 \%$. Кроме того, отмечаются различия в классе бонитета.

Абрикос обыкновенный (Armenica vulgaris L.) находит определенное применение в защитном лесоразведении. В лесополосах при первоначальной густоте создания 2222 шт./га (размещение 3,0 x 1,5 м), ширине 12,0 м, в возрасте 21 года (пробн. площадь 6) он достигает диаметра $10,8 \mathrm{~cm}$, ветрозащитной высоты 7,5 м, сохранности породы $71,8 \%$ и запаса $60,8 \mathrm{~m}^{3} /$ га. Четырехрядное насаждение в лесоводственно-мелиоративном плане оценивается по шкале 4 балла, конструкция - ажурная, что вполне приемлемо для данных почвенно-климатических условий.

В возрасте 28 лет в лесной полосе, созданной из пяти рядов при размещении $3,0 \times 1,0$ м, сохранность акации белой равна $61,5 \%$, груши лесной (Pyrus communis L.) $50,8 \%$, шелковицы (Morus alba L.) - 58,3\%. Биометрические показатели роста акации белой по диаметру составляют 17,2 см, груши лесной 9,1 см, шелковицы - 15,0 см, высота соответственно 15,6, 6,8 и 14,1 м. Акация белая произрастает по Іа бонитету, груша лесная по III и шелковица по I. На- саждение имеет ажурную конструкцию и оценивается по шкале акад. Е.С. Павловского 56 (пробн. площадь 9).

В возрасте 25 лет в защитном насаждении, созданном из четырёх рядов при размещении растений $3,0 \times 1,0$ м, сохранность тополя равна $40,1 \%$; груши лесной $69,5 \%$; яблони - $69,5 \%$; акации белой $-56,3 \%$. Биометрические показатели роста тополя по диаметру составляют 20,4 см, акации белой $-15,1$ см, груши лесной $-8,0$ см, яблони - 7,2 м, по высоте соответственно $17,6,14,0,6,5$ и 6,1 м. Тополь и акация белая произрастают по Іа бонитету, груша лесная и яблоня по III. Насаждение имеет ажурную конструкцию и оценивается по шкале акад. Е.С. Павловского 46 (пробн. площадь 10).

Таким образом, лесомелиоративные комплексы в лесоаграрных ландшафтах должны обеспечивать полную защиту сельскохозяйственных угодий от неблагоприятных природных явлений, эрозионных процессов, повышать экологическую ёмкость территорий. Все мероприятия по благоустройству агротерриторий должны проводиться в сжатые сроки с использованием современных технологий и с учётом эколого-ландшафтной системы земледелия.

Древесные породы в защитных насаждениях в различных почвенных условиях имеют отличительные показатели роста (табл. 2). 
Таблица 2

Рост древесных пород в искусственных защитных линейных насаждениях, м

\begin{tabular}{|c|c|c|c|c|}
\hline \multirow{2}{*}{$\begin{array}{c}\text { Возраст, } \\
\text { лет }\end{array}$} & \multicolumn{3}{|c|}{ Почва } \\
\cline { 2 - 5 } & Чернозём обыкновенный & \multicolumn{2}{|c|}{ Чернозём южный } \\
\cline { 2 - 5 } & Акация белая & Гледичия обыкновенная & Акация белая & Гледичия обыкновенная \\
\hline 4 & 0,9 & 1,2 & 0,7 & 1,1 \\
\hline 12 & 4,3 & 5,0 & 4,1 & 4,7 \\
\hline 18 & 6,2 & 7,1 & 5,8 & 6,3 \\
\hline 30 & 12,3 & 13,4 & 11,7 & 12,3 \\
\hline
\end{tabular}

Таблица 3

Характеристика древесных пород в разных рядах насаждений

\begin{tabular}{|c|c|c|c|c|c|c|c|c|}
\hline \multirow{2}{*}{$\begin{array}{c}\text { № } \\
\text { пр. }\end{array}$} & \multirow{2}{*}{$\begin{array}{c}\text { Возраст, } \\
\text { лет }\end{array}$} & \multirow{2}{*}{ Порода } & \multicolumn{2}{|c|}{ Крайние ряды } & \multicolumn{2}{|c|}{ Центральные ряды } & \multicolumn{2}{c|}{ Различия, \% } \\
\cline { 4 - 7 } & & \multicolumn{4}{|c|}{ Показатели высоте } & по диаметру \\
\cline { 4 - 7 } & & $\begin{array}{c}\text { высота, } \\
\text { м }\end{array}$ & $\begin{array}{c}\text { диаметр, } \\
\text { см }\end{array}$ & $\begin{array}{c}\text { высота, } \\
\text { м }\end{array}$ & $\begin{array}{c}\text { диаметр, } \\
\text { см }\end{array}$ & & \\
\hline 11 & 26 & Орг & 10,1 & 13,3 & 12,0 & 12,2 & 15,8 & 8,3 \\
\hline 12 & 23 & Акб & 12,0 & 15,9 & 13,8 & 14,0 & 13,0 & 12,0 \\
\hline 13 & 28 & Гло & 13,4 & 17,4 & 15,7 & 15,9 & 14,7 & 8,6 \\
\hline
\end{tabular}

На чернозёме обыкновенном акация белая к возрасту 30 лет имеет по высоте средний прирост 0,41 м/год, на черноземе южном - 0,39 м/год. Для гледичии обыкновенной (Gleditsia tricanthos L.) такие различия составляют соответственно 0,44 и $0,40 \mathrm{~m} /$ год. В лесных полосах активность в росте изменяется с учетом возрастных показателей. На черноземе обыкновенном у акации белой имеется снижение энергии роста в возрасте 15-19 лет, на чернозёме южном - 16-18 лет. Гледичия обыкновенная характеризуется более активным ростом в высоту до возраста 19-21 год, на чернозёме южном 18-20 лет. Данные закономерности характеризуют их эколого-биологические свойства, которые необходимо учитывать при подборе пород в схемах смешения. Более значимые показатели роста в высоту у акации белой и гледичии обыкновенной отмечаются на чернозёме обыкновенном по сравнению с показателями роста на чернозёме южном.

Древесные породы в зависимости от физиологических показателей, влияющих на их рост, имеют различия в биометрических параметрах в разных рядах произрастания (табл. 3).

Защитные насаждения в возрасте 2328 лет на чернозёме обыкновенном из ореха грецкого, акации белой и гледичии обыкновенной формируют выпуклый поперечный профиль (пробн. площадь 11, 12 и 13). Для ореха грецкого характерны наибольшие различия в росте по высоте крайних и цен- тральных рядов (15,8\%). У гледичии обыкновенной такая закономерность составляет $14,7 \%$, акации белой - $13,0 \%$. Различия в росте по диаметру наибольшее значение имеют акация белая (12,0\%), гледичия обыкновенная и орех грецкий - 8,3-8,6\%. Такая особенность произрастания в искусственных культурах способствует иметь наиболее оптимальный профиль по аэродинамическим характеристикам биологических объектов. Это позволит защитить дополнительно приполосную зону на пашне.

\section{Заключение}

1. Защитные насаждения в возрасте 25 лет (размещение 3,0 x 1,0 м) представлены тополем бальзамическим, яблоней и грушей лесной, где при ширине 12,0 м формируется ажурная конструкция, которая вполне приемлема для обустройства агротерритории лесомелиоративными комплексами. Тополь превосходит по биометрическим показателям роста сопутствующие породы в 1,35-2,88 раза, что обусловлено его биологическими особенностями.

2. В искусственных лесных насаждениях с участием акации белой, гибридных тополей, яблони и груши лесной шириной $12,0-15,0$ м с размещением растений 3,0 х 1,0 м в возрасте 25-28 лет акация имеет сохранность 56,3-61,5\%, отстает в росте от тополя по диаметру на 5,3 см, высоте на 3,6 м, превосходит по биометрическим показателям шелковицу на 9,6-47,1 \%, яблоню лесную - на 52,3-56,4 \%, грушу лесную - 
на 47,1-56,5\%. Запас стволовой древесины достигает 95 и 138 м³/га, сформировалась ажурная конструкция.

3. Груша лесная - хорошая сопутствующая порода в защитном лесоразведении Краснодарского края. В противоэрозионных насаждениях в возрасте 28 лет из шелковицы, груши лесной и акации белой главная порода превосходит по биометрическим показателям в росте и сохранности сопутствующие. Для уменьшения изъятия пахотных земель ширина стокорегулирующих лесополос не должна превышать 15,0 м.

4. Лесные полосы в возрасте 8 лет из ясеня зеленого имеют средний диаметр 4,2 см, среднюю высоту - 9,8 м, сохранность 78,9\%. При ширине междурядий 2,5 м и 5 рядах формируется ажурная конструкция. Для повышения эффективности насаждений во вновь создаваемых лесомелиоративных комплексах следует формировать оптимальное количество рядов.

5. Лесомелиоративные насаждения шириной 10,0-12,0 м чистые по составу из абрикоса обыкновенного в возрасте 9-21 года имеют высоту 3,4-7,5 м, диаметр 4,8-10,8 см и сохранность - 68,2-71,8\%. В них формируется ажурная конструкция. Для повышения мелиоративных свойств и уменьшения изъятия пахотных земель из оборота целесообразно ширину защитного насаждения принимать не более 15,0 м.

6. Орех грецкий занимает значительные площади в защитном лесоразведении Краснодарского края. В лесных полосах с его участием в возрасте 17 лет при ширине 15,0 м обычно формируется ажурная конструкция. Диаметр ореха грецкого составляет $12,2 \mathrm{~cm}$, высота - 7,2 м.

7. В лесных насаждениях в возрасте 23-28 лет из ореха грецкого, акации белой и гледичии обыкновенной сформирован выпуклый профиль, где крайние ряды имеют больший диаметр на 8,3-12,0\% и отстают в росте по высоте на 13,0-15,8\%.

8. Лучший рост акации белой, гледичии обыкновенной и ореха чёрного отмечается на чернозёме обыкновенном, чем на чернозёме южном.

\section{Список литературы / References}

1. Дубинок Н.Н., Танюкевич В.В., Тюрин С.В., Состояние и лесомелиоративная эффективность полезащитных лесонасаждений Краснодарского края // Российская сельскохозяйственная наука. 2017. № 1. С. 36-38.

Dubinok N.N., Tanyukevich V.V., Tyurin S.V., Condition and meliorative efficiency of protection plants in Krasnodar region // Rossiyskaya sel'skokhozyaystvennaya nauka. 2017. No. 1. P. 36-38 (in Russian).

2. Караманян А.С., Михина Е.А., Михина В.В. Рост, формирование полезащитных насаждений Кореновского района Краснодарского края // Докучаевское наследие и развитие научного земледелие в России. Воронеж: Истоки, 2017. C. $221-223$.

Karamanyan A.S., Mikhina E.A., Mikhina V.V. Growth, formation of shelter plantations Korenovsky district of Krasnodar Territory // Dokuchayevskoye naslediye i razvitiye nauchnogo zemledeliye v Rossii. Voronezh: Istoki, 2017. P. 221223 (in Russian).

3. Танюкевич В.В. Продуктивность и мелиоративная роль лесных полос степных агролесоландшафтов. Новочеркасск: Лик, 2012. 175 с

Tanyukevich V.V. Productivity and reclamation role of forest strips of steppe agroforestry landscapes. Novocherkassk: Lik, 2012.175 p. (in Russian).

4. Турусов В.И., Лепёхин А.А., Чеканышкин А.С. Опыт лесной мелиорации степных ландшафтов: монография. ФГБНУ «НИИСХ ЦЧП». Воронеж: Истоки, 2017. 228 с.

Turusov V.I., Lepyokhin A.A., Chekanyshkin A.S. Amperesecond. Experience of forest melioration of steppe landscapes: monografiya. FGBNU «NIISKH TSCHP». Voronezh: Istoki, 2017. 228 p. (in Russian).

5. Проездов П.Н., Маштаков Д.А. Агролесомелиорация. Саратов: Амирит, 2016. 472 с.

Proezdov P.N., Mashtakov D.A. Agrolesomelioraciya. Saratov: Amirit, 2016. 472 p. (in Russian).

6. ОСТ 56-69-83. Площадки пробные лесоустроительные. Методы закладки. М.: Издательство стандартов, 1984. $60 \mathrm{c}$.

OST 56-69-83. Ploshhadki probnye lesoustroitel'nye. Metody zakladki. M.: Izdatel'stvo standartov, 1984. 60 p. (in Russian).

7. Кудряшов Н.Н. Вариационная статистика: учебное пособие. Пенза: ФГБОУ ВО Пензенский ГАУ, 2018. 131 с.

Kudryashov N.N. Variational statistics: a training manual. Penza: FGBOU VO Penzenskiy GAU, 2018. 131 p. (in Russian). 